\title{
Being 'post-academic'
}

Real Science: What it is and what it means by John Ziman

Cambridge University Press · April 1999

Hardback $£ 25 / \$ 39.95$

Peter L. Hordijk and Eloise C. Anthony

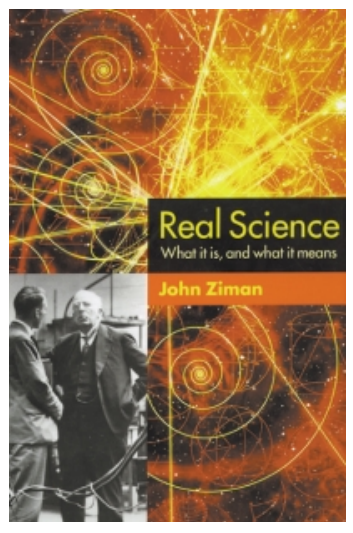

W

hy is it that most research projects nowadays end with such vague statements as "the results of these studies may open up new avenues for therapeutic intervention" or an equivalent? What happened to pure scientific research simply aimed at the advancement of knowledge? These and related questions are extensively addressed in Real Science: What it is and what it means. The transition of scientific research and its methods from academic to 'post-academic' (from basic research to applied research) over the past 50 years or so is the central theme of Ziman's book.

Scientists are driven by curiosity, which is an individualistic virtue. As a result, scientists favour curiosity as it implies autonomy. However, the image of the scientist as the independent'lone seeker after the truth' is no longer very realistic. Ziman puts a lot of emphasis on the social aspects of scientific endeavour and clearly highlights the contrast between the idealized image of scientific research being purely objective and the everyday reality in which the gathering of scientific knowledge is driven by personal, societal or even corporate interests. Science has become more and more integrated in society, not least because of its basic role in economic progress. In addition, some scientific fields have developed into 'Big Science'. An example is nuclear physics, in which researchers work in large teams with huge equipment requiring vast amounts of money. As a result of these developments, academic science has become part of a national 'Research and Development' effort.

As for the scientists themselves, they have been put in a situation of fierce competition for grants or contract research. On the one hand, to enable them to do original research, they have to be highly specialized. However, on the other hand, they also require knowledge of related fields as well as of the possible utility of their findings, because of the pressure to give more 'value for money'. Although Ziman spends little time on it, the way in which scientific knowledge is now acquired has been immensely altered by the introduction of computers. This has speeded up knowledge acquisition, providing new and previously impossible means of analysis and promoting communication, which, as Ziman points out, is such a vital aspect of the process of producing scientific knowledge. These aspects put further demands on postacademic scientists to be skilled investiga tors, alert technical innovators and competent communicators.

Zinman also mentions that an observation in scientific research may become an accepted 'fact' providing that it is reproducible and is referenced in subsequent reports by other scientists, and that it also fits into the prevailing models of that particular subject at that particular time. Consequently, the direction taken by contemporary science is determined by the choices made by the researchers themselves, who, when writing their grant proposals, determine not only what knowledge will be added to the archive, but also which subjects will not be studied.

Although Ziman states in the first chapter that the book is written for laymen, one doubts whether he will actually reach the public. This is not only because of the style of the language used throughout the book but also the fact that the processes Ziman describes can probably be best understood by those who participate in scientific research on a regular basis. The book has an extensive bibliography and index and is pleasantly divided into brief chapters. It will certainly be of interest to experienced researchers, but also to newcomers who wish to learn about scientific methods, provided that the first chapter does not daunt them too much!

Ziman does provide an excellent insight into the social and 'political' structure of the scientific world. He explains much of scientific etiquette and its origin, which is not always apparent to budding scientists. Furthermore, he explains how the world of science polices its members, which is often a matter of concern to the uninformed layman. O bjectivity and rationality are key con- cepts throughout the book. Their limitations to scientific data are aptly described, which allows the reader a new perspective of results obtained within the scientific community. The scientific world is also depicted as one of the very few societies in which equality is paramount, be it class, gender, ethnicity or simply radical scientific ideology. Ziman explores how the latter often generates serendipitous results, which in turn open up new avenues of research no matter how controversial the initial idea. The way in which such a unique community has evolved while still remaining relatively immune to common human prejudices is thus described with all the ensuing pros and cons.

Overall, Real Science makes interesting reading because it shows that scientific knowledge, rather than providing the idealized, clear and concise description of the world around us, is all too much an evolving product of the human mind. As we all know, the human mind has many inherent limitations and bias and is subject to more personal and environmental influences than most scientists might think! Peter L. H ordijk and Eloise C. Anthony are in the Department of Experimental Immunohematology, CLB and the Laboratory for Experimental and Clinical Immunology, University of Amsterdam, The Netherlands email:P_Hordijk@CLB.n

\section{New in Hardback}

The Flagellates: Unity, Diversity and Evolution edited by Barry S. C. Leadbeater and J. C. Green

Taylor and Francis, £80/\$130

\section{New in Paperback}

Plant Life

by A. R. Ennos and Elizabeth Sheffield Blackwell, £25/\$37 